Journal of Engineering and Applied Sciences 14 (Special Issue 7): 9923-9935, 2019

ISSN: 1816-949X

(c) Medwell Journals, 2019

\title{
Feasibility Study of Applying a Pattern Waterflood Without and with Peripheral Injectors for Maximizing Oil Recovery Under Limited Water Sources Availability A Case Study of Heterogeneous Giant Carbonate Reservoir
}

\author{
Wisam Iessa Taher and Sameera Mohammed Hamd-Allah \\ Department of Petroleum Engineering, College of Engineering, University of Baghdad, \\ Baghdad, Iraq
}

\begin{abstract}
The full reservoir under study is Mishrif reservoir of Y oil field which is an Iraqi giant carbonate reservoir mainly consists of limestone rocks that belong to Late Cenomanian age with average total thickness around 400 mand OIIP close to 10MMMSTB. Mishrif reservoir started to produce since, May, 2005 by primary recovery but the reservoir pressure is significantly declined over the past 5 years due to sharply increasing of oil production and the current reservoir pressure around many wells is slightly exceeded saturation pressure, although, pilot water injection program had been executed since, May, 2015. Due to the limitation of available water for injection around Y field, there's a necessity to optimize the use of this limited water resource through a proper water flooding design and an efficient development scenario to achieve the maximum oil recovery and the longest life cycle of this of carbonate reservoir. In this study, based on three dimensional simulation model matched, a full-field development plan under water flooding secondary recovery was designed by using conventional reservoir simulation for around 23 years of prediction for meeting with the field operator's strategic production requirements. One strategy of pattern water flood has been proposed with modified staggered line drive pattern to achieve a field production plateau rate of $300 \mathrm{MSTB} / \mathrm{D}$ by progressively adding 124 new producers and 96 injectors. For providing an additional support to pattern water flooding for maximizing oil recovery from the reservoir under study, another strategy is planned with adding 40 new peripheral injectors along reservoir periphery to pattern flood strategy with maintaining of field production plateau rate and number of producers of pattern flood strategy. The results of feasibility analysis showed that the addition of peripheral wells is an unfeasible choice because of gaining a comparatively small profit in final oil recovery, around $0.77 \%$, through exploiting a great amount of water injected in these new wells which required more additional expenditures and further water resources for injection purposes that have not available around the field under study.
\end{abstract}

Key words: Carbonate reservoirs, pattern water flood, peripheral waterflood, hetrogenous reservois, improved oil recovery, development

\section{INTRODUCTION}

The economic significance of carbonate reservoirs is great in oil industry around the world. More than half of the world's remaining oil are existing in carbonate reservoirs. These reservoirs are among the most complex reservoir to characterize and manage due to high heterogeneity of reservoir properties which leads to more uncertainty in the regins a far from wells locations (Akber et al., 2000). As the primary drive energy of a reservoir depletes, there is a necessity to seek about other methods of oil recovery from existing known accumulations. Conventional water flooding is the most widely used secondary recovery process due to water is extensively available and low-cost relative to other injected fluids, easy to inject and considerably efficient in displacing oil (Ahmed, 2010).
In perfect conditions, the injected water into the reservoir will sweep oil from the injectors in the direction of the producers that get oil produced to the surface. However, in real situation, this process does not taken place so simply. The reservoir heterogeneity in terms of rock and fluid properties that are varied spatially depends on depositional environments and subsequent events. Thus, the injected water will highly flow through the simplest paths with less resistance that are normally high strike permeability layers and conductive fractures. This situation will cause bypasses more amount of oil and get its far from the producers. Moreover, more water will produce with time up to reach a point where the water injection becomes an unfeasible choice regarding economical consideration. Unfortunately because of poor sweep efficiency just around 33\% of the oil initially in place is recovered even though with implementing of water flooding project (Smith and Cobb, 1997). 


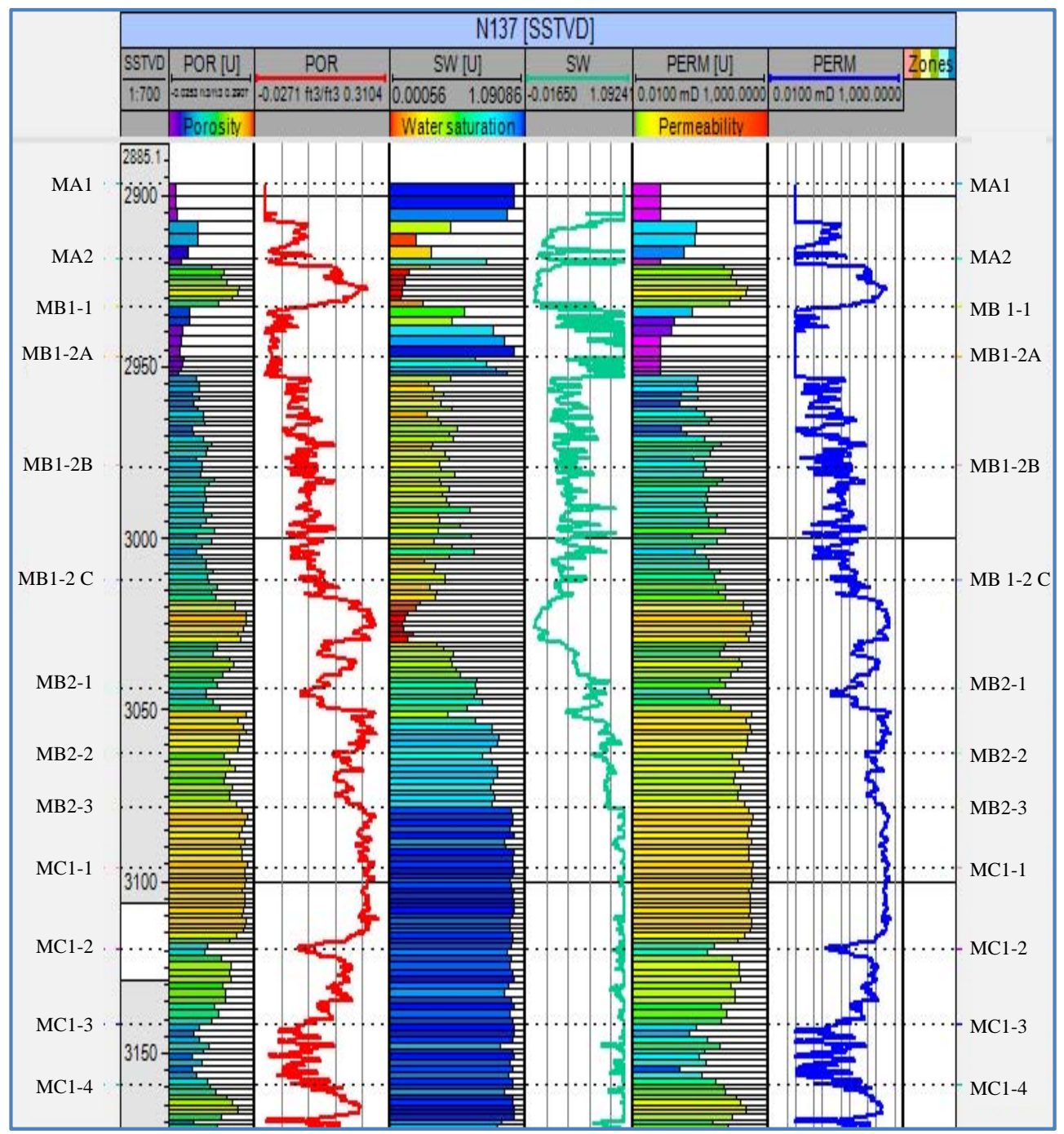

Fig. 1: Reservoir units and petrophysical properties for Mishrif reservoir (Well N137)

The repeated patterns are widely adopted, although, the geological and reservoir characteristics heterogeneity have not been highly taken into account in the placement of these flood patterns. On the other hand, there are many researches about irregular or modified well pattern, especially on the studying a sedimentary micro facies, directional reservoir permeability and the pattern for highly deviated, horizontal and multilateral wells. Hence, the old principle regarding constant density of well spacing is not appropriate for these complex wells (highly deviated, horizontal and multilateral wells) and modified well pattern should be applied (Liu and Sun, 2017). Regarding peripheral flooding, injectors are spread along the reservoir flanks. This pattern type is commonly applied to reservoirs with reasonable dip angle, so as to take some advantage of this formation dip through oil displacement by injecting water (Singh and Kiel, 1982).
The main objective of this study is to design an optimal water flood strategy by pattern waterflod as well as assess the viability of applying peripheral waterflood to provide an additional support to pattern waterflood strategy for improving oil recovery in Mishrif carbonate reservoir with more restrictions about water availability for injection purposes (Fig. 1).

Background of reservoir under study: Mishrif is the main reservoir in $\mathrm{Y}$ oil field and mainly consists of limestone rocks which are belong to Late Cenomanian age. Total formation thickness varies from 391-417 m, averaging about $400 \mathrm{~m}$. Y oil filed is a gentle elongated anticlinal structure with its long axis extending in a NW-SE direction about the structure is approximately $32 \mathrm{~km}$ long by $8.8 \mathrm{~km}$ wide. Based on sequence stratigraphy well log analysis and core description, the 
reservoir under study is subdivided into 4 main units: MA, MB1, MB2 and MC1 that included13 subunits from top to bottom as shown in Fig. 1. There are a significant barrier exists between unit MA2 and MB1-1 which separates the entire reservoir into two sub reservoirs with edge/bottom aquiferand different pressure systems in MA and "MB1-MC1" (Main Mishrif).

Up to June, 2010, eight wells have been drilled in Mishrif reservoir of Y oil field. The deepest well reached a depth of 4,788 m, down to the Lower Cretaceous Sulaiy formation. 3D seismic acquisition was started in November, 2010 and completed in July 2011, covering a total area of $496 \mathrm{~km}^{2}$. The first new well was spudded at the end of 2010 and a total of 197 new wells have been completed drilling in all reservoir of $\mathrm{Y}$ field as of June, 2017. In April, 2005, Y field production began from Mishrif reservoir by one well only up to December, 2011.

\section{MATERIALS AND METHODS}

Geological model: A high resolution three dimensional geological model was built through using "Petrel" Software to characterize the stratigraphic, structural and petrophysical properties distribution along the Mishrif reservoir. This model is constructed based on geophysical, geological, pertophysical and engineering information that have been gotten from around 60 available wells penetrating Mishrif formation in $\mathrm{Y}$ oil field. In this geological model, a 2D geological surfaces for all Mishrif subunits have been generated depend on well tops data and the structural map of top formation. Figure 2 shows the structural map of top main unit MA (Top Mishrif).

The grid system in the geological model consists of 163 sublayers through the vertical direction to describe the high vertical heterogeneity of the reservoir and $160 * 383$ grid cells in $\mathrm{x}-\mathrm{y}$ direction with 9,988, 640 total grid cells. Well logs scale up is performed for all wells available for averaging log data for each layer in the model through using athematic and geometric averaging methods. Sequential Gaussian Simulation algorithm were applied to populate rock properties and fluid saturations through 3D grid cells in regions far from wells locations. The estimated initial oil in place of Mishrif reservoir by this geological model is about 9,661 MMSTB of which main unit MB1 accounts for about $72.8 \%$ while MA, MB2 and MC1 account for 7.7, 14.3 and 5.2\%, respectively.

Production and injection history: The dynamic period of Mishrif simulation model is more than 12 years that is from May, 2005 to August, 2017. Up to December, 2011, there was only one production well which produced from Mishrif reservoir in $\mathrm{Y}$ oil field. After that there were more wells progressively put on production from Mishrif to increase the production capacity of the reservoir. At end of July, 2017, there were around 88 active producers with production rate around 149 MSTB/D for whole Mishrif reservoir. In addition, the average individual well production around 1800 STB/D, water cut about 3.34\%, and GOR 645 SCF/STB. The GOR is stable for reservoir pressure higher than saturation pressure. In addition, the low water cut vlaues and high reservoir pressure decline indicate that the natural energy of Mishrif reservoir is not enough for this production rate. Consequently, along the production history of Mishrif reservoir, a relatively weak water drive and depletion have been the main production mechanisms as stated by the quick analysis of production behavior of Mishrif reservoir.

Pilot water injection in Mishrif reservoir started when one production well (M325) as the first well was converted to injector with water injected through all perforation intervals in May, 2015. Subsequently, the second pilot well (M279) was converted to Injector and with water injected from only bottom reservoir (main unit MC1), in May, 2016. In July, 2017, the water injection rates for well M325 and well M279 were about 6,000 and 9000 STBw/D, respecively.

The cumulative oil production, oil prodution rate, cumulative water injection, and water injection rate for Mishrif reservoir up to August, 2017 are presented in Fig. 3.

Simulation dynamic modeling: Before constructing a simulation model, the upscaling process of multi millions geological model has was achieved to minimize run-time in dynamic simulation model with almost preserving the high reservoir heterogeneity. After that, a three dimensional three phase single porosity dynamic simulation model was developed depending on the geological model outputs and a set of available field data. This model is built to simulate fluid flow through reservoir during a production history for around 12 years and pilot water injection history for about two years.

In this model, two PVT regions and four saturation regions are executed in to represent the vertical variation of oil properties and rock-fluid physical properties, respectively. Through model initialization, Mishrif reservoir has been divided into two equilibration regions, consistent with the fluid model and pressure systems in Mishrif, the first one comprises MA and the second one vertically extends from MB1 to MC1. In the first region, initial pressure is 5005 psia at a datum depth of $2950 \mathrm{mSS}$ and oil water contact at $3017 \mathrm{mSS}$. On the other hand, initial pressure was set 5030 psia at a datum depth of $3050 \mathrm{mSS}$ andoil water contact at 3,070 mSS for the second region. The vertical distribution of resulting water saturation and initial pressure are presented in Fig. 4 and 5. In addition, arelatively weak water drive aquifer by Fetkovich Model has been found to be best represented through the history matchingin dynamic period of the model. 


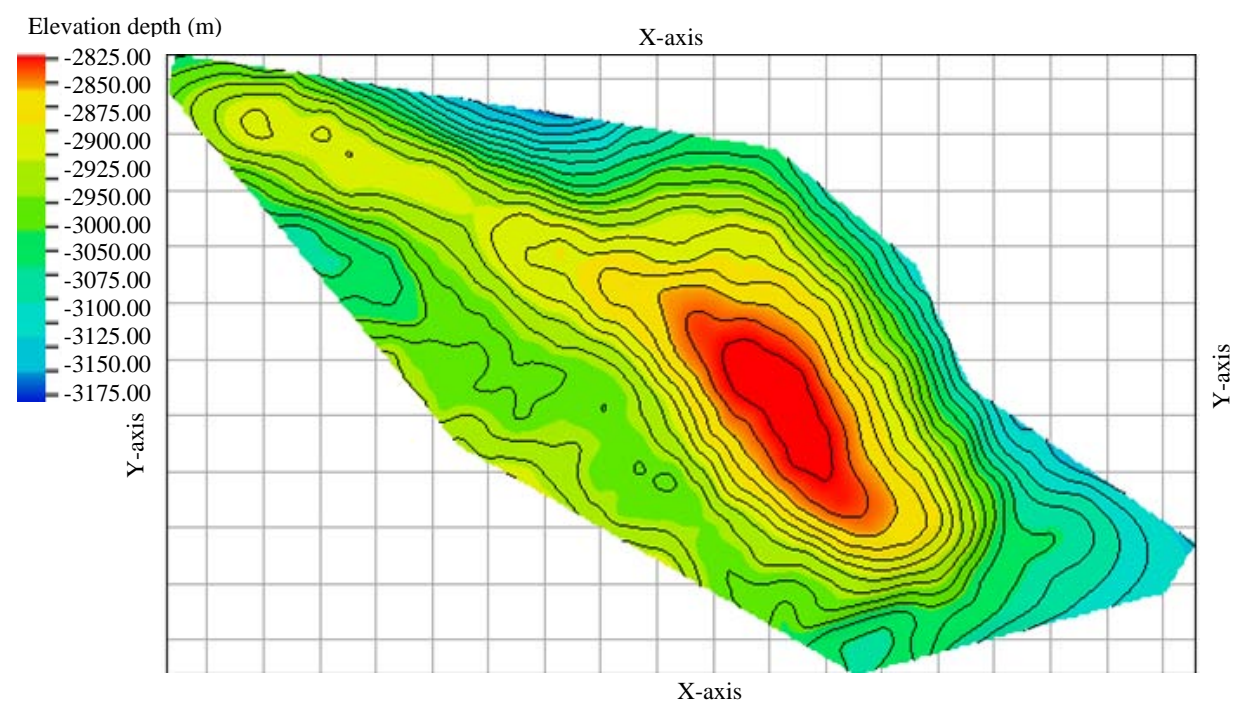

Fig. 2: Structural map of top Mishrif (Top main unit MA)

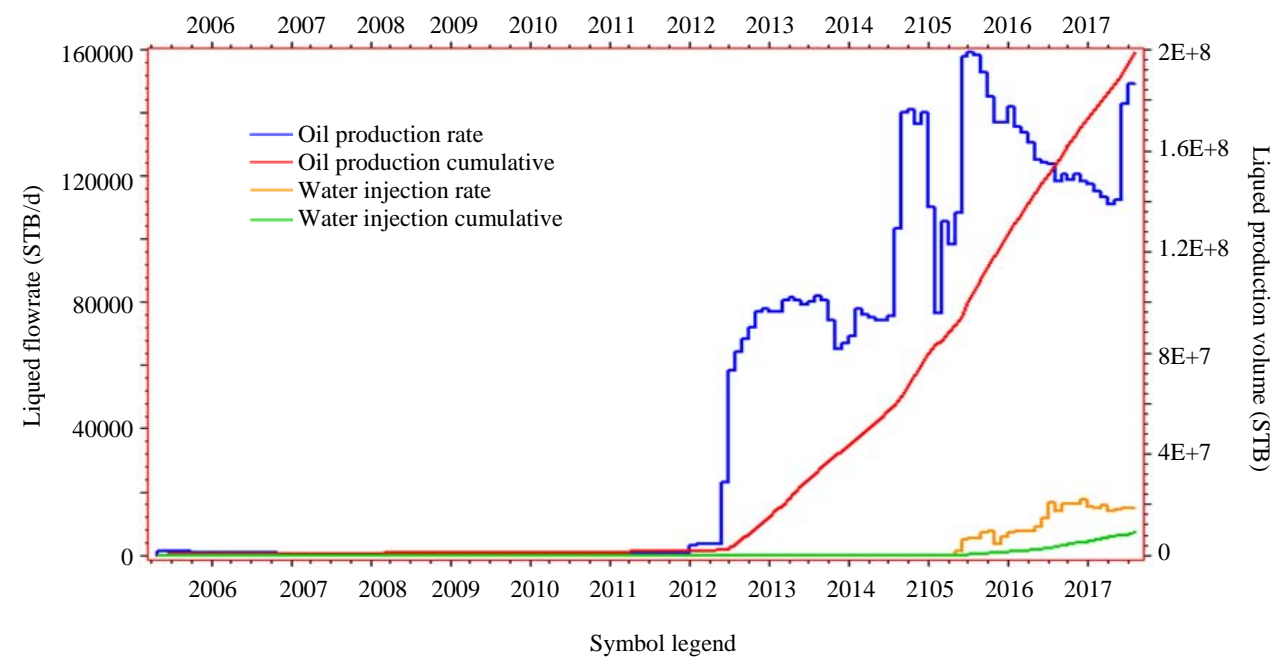

Fig. 3: Production and injection history of Mishrif reservoir

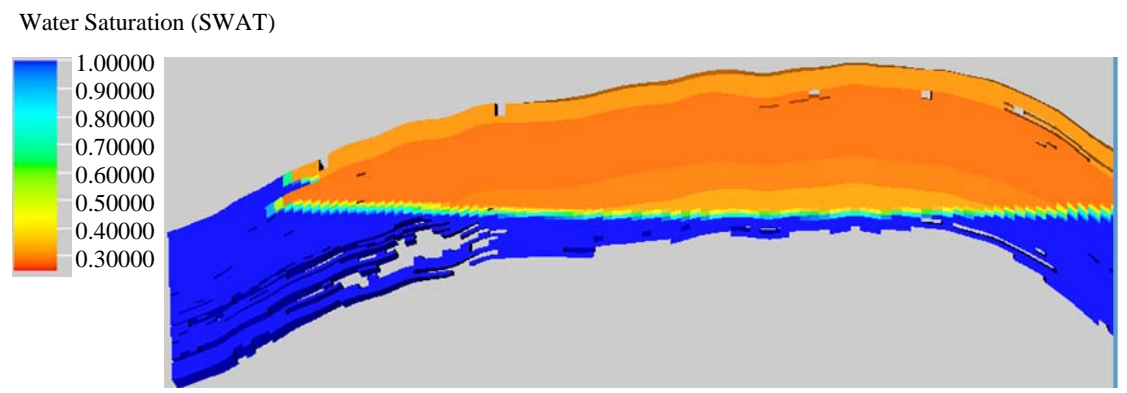

Fig. 4: Vertical distribution of Mishrif initial water saturation

In term of well modeling in the simualtion model, there were around 100 wells with different well types (vertical, deviated, horizonatal and multilateral) that drilled and completed in Mishrif reservoir through few 


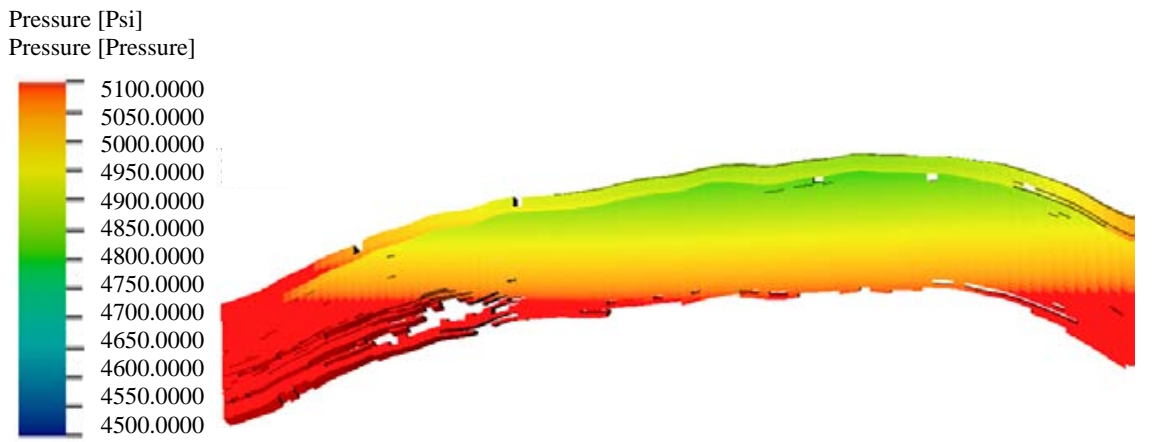

Fig. 5: Vertical distribution of Mishrif initial reservoir pressure

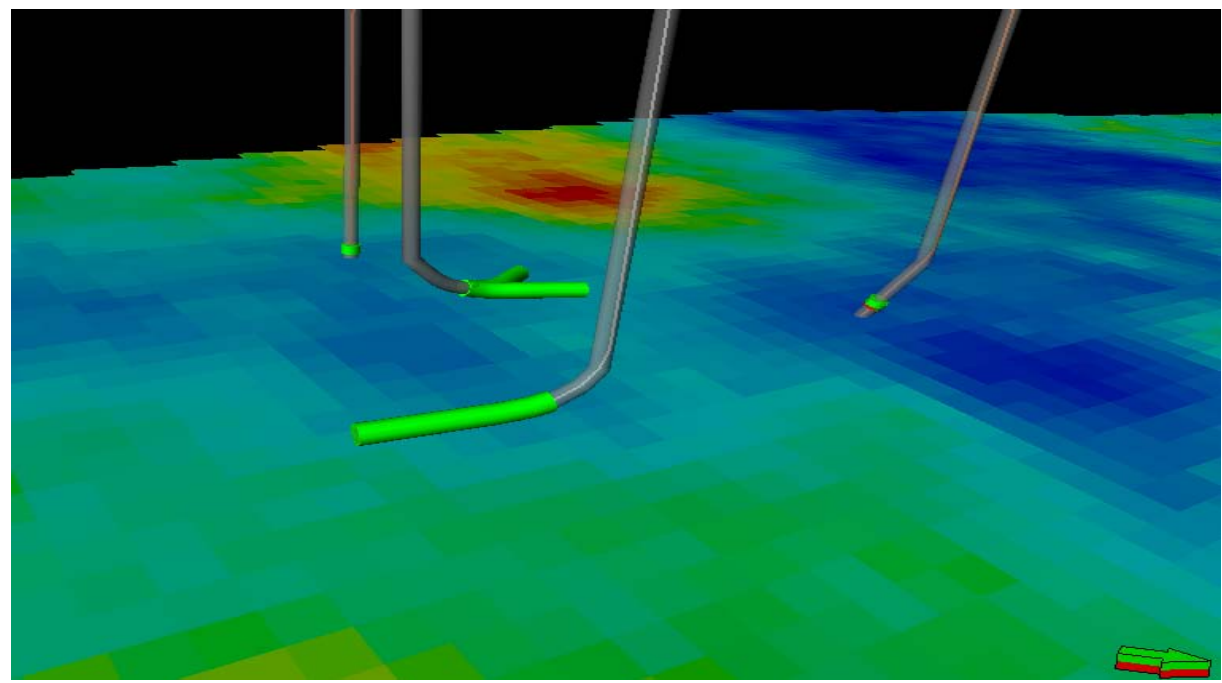

Fig. 6: An example of various well types and completions in Mishrif

years ago. For well completion modeling, variuos well completion types are utilized in the simulation model. Vertical and deviated wells are completed by cased hole completion with perforating one or more layers. In horizontal and multilateral wells well completions are simulated by casing with using perforated liner along the horizontal section. Fig. 6 displays example of different well types and completions in Mishrif reservoir.

The oil initially in place estimated by this dynamic model through initialization process is very close to that estimated in geocellular model with difference $<1 \%$. In addition, the validation of dynamic model is achieved through history matching process for both individual wells and entire reservoir regarding of oil production rate, water injection rate, produced water cut and static pressure during the whole simulation time. In general, the history matching results introduced highly acceptable match with very good trend along total dynamic simulation period for entire reservoir and most of wells in the reservoir. Accordingly, this model can be utilized to realistically forecast the reservoir performance in the future under waterflooding and other strategies.

Development plan: Two development strategies under full field waterflooding would be proposed for future prediction performance with period about 23 years, extending from August, 2017 to March, 2040 in correspondence with the actual field operating conditions. Through these two strategies, more vertical, deviated and horizontal producers and vertical injectors is drilled and some of existing production wells have been gradually converted to injectors. The optimal development strategy of the reservoir under study should be selected to achieve a reasonable production plateau period, optimum oil recovery and delay water breakthrough as far as possible as well as optimum water injected volume due to some restrictions regarding water injected availability around field area. 
Adding new producers: For each proposed waterflood strategy, more new producers with different well types and new vertical injectors are suggested to drill also some of existing producers have been progressively converted to injectors. The total number of new drilled producers are identical through both two proposed waterflood strategies but number of new injectors is different for every strategy. Accordingly in both waterflood strategies, 124 new producers including 17 verticals, 55 deviated and 52 horizontal wells have been drilled in regions with high oil saturation, reasonably good reservoir properties and significant distant from OWC and completed in different producing zones of Mishrif reservoir. The average oil production rate of each new producer is basically depended on reservoir properties, pressure and well and field constraints but normally ranged from 1,000 STB/D to 2,500 STB/D for vertical and low deviated wells, and ranged from 1,500 STB/D to 4,000 STB/D for highly deviated and horizontal wells.

Configuration of new wells: According to reservoir characterization and production performance, many well types and configurations are proposed for new producers and injectors in the current development plan. In regarding of new production wells configuration, vertical and low deviated wells are properly suggested to drill in the regions that have a high reservoir permeability, thick oil column and target zones far from OWC. The completion of these well types is typically cased hole completion with selective perforated intervals. Conversely, horizontal new producers are proposed to be an efficient option in the areas with moderate and small oil zone thickness and reasonable vertical transmissibility. Furthermore, the new horizontal wells have been distributed along the reservoir oil zone which has large amounts of remaining oil. The completion type for the new horizontal wells will be proposed as perforated liner completion with lateral length ranges from 1000-1500 m which can achieve high productivity from reservoir as large reservoir area will be exposed to the horizontal section. On the other hand, for waterflooding purposes, new injectors are suggested to be designed with only vertical well type in all regions of the reservoir under study with cased hole completion through selective perforated intervals.

Production and injection well controls: To provide long term prediction for development plan, many constraints are governed the existing and new production wells and the existing two pilot injectors and new injectors. For production wells, maximum oil production rate was set equal to 7,000 for vertical and low deviated wells and 9,000 STB/D for horizontal, highly deviated and multilateral wells. For economic considerations an economic limit of $100 \mathrm{STB} / \mathrm{D}$ for a single well was also introduced to the model as a minimum oil production rates for all types of producers. Regarding bottom hole pressure, all production wells were allowed to produce down to 2,700 psia to avoid any free gas production if the pressure drops below saturation pressure of the reservoir. In addition, for water cut restrictions, based on the surface facilities capacity of the field operator, well connections and entire wells were shut down when the water cut reached to $90 \%$.

On the subject of the control rules for existing and new injectors, the maximum injection rate per well is fixed equal to 12,000 STB/D. Such control was applied for all new injectors and converted wells in the future. Also, the maximum bottom hole pressure was set equal to 6,500 psia for all injectors to prevent formation fracturing due to reaching of Mishrif fracturing pressure at this pressure value.

Waterflood design: The proper design of waterflood project is a crucial issue to achieve the optimal development plan of Mishrif reservoir. Design anexcellent waterflood strategy for giant heterogeneous carbonate reservoir with more restrictions and uncertainties about water availability is highly difficult task and acts a big challenge, especially with existing around hundred wells already drilled in the reservoir with different well types; vertical, deviated, horizontal and multilateral wells.

The planned field development strategy in the current work rely on a full field waterflooding by two strategies to supplement the reservoir energy and significantly improve the recovery. These two waterflood strategies included one strategy by staggered line drive pattern only and another by adding peripheral injectors to pattern waterflood strategy for providing more pressure support and maximizing oil recovery. In both two strategies, the duration for future prediction performance is about 23 years, extending from 1st August, 2017 to 1st March, 2040 in agreement with the actual field operating conditions. Moreover, according to planned schedule of field operator, plateau period should be started in April, 2019 which is applied for two proposed water flood strategies in the current work. Regarding injection wells, the new injectors and converted wells are suggested to be added progressively from 2018-2030 and distributed in areas with practically low regional pressure and relatively good reservoir properties. These strategies are designed with target production plateau rate of $300 \mathrm{MSTB} / \mathrm{D}$ for whole Mishrif reservoir.

In Mishrif reservoir, there are three main production regions; Middle, South East and North West. Most of the existing production wells are concentrated in the crest area. In the current work, the target zones for injection are different from the crest to the flank and from one production region to another depending on the reservoir heterogeneity and continuity and local barriers distributed. According to many sectorial tests executed through model 


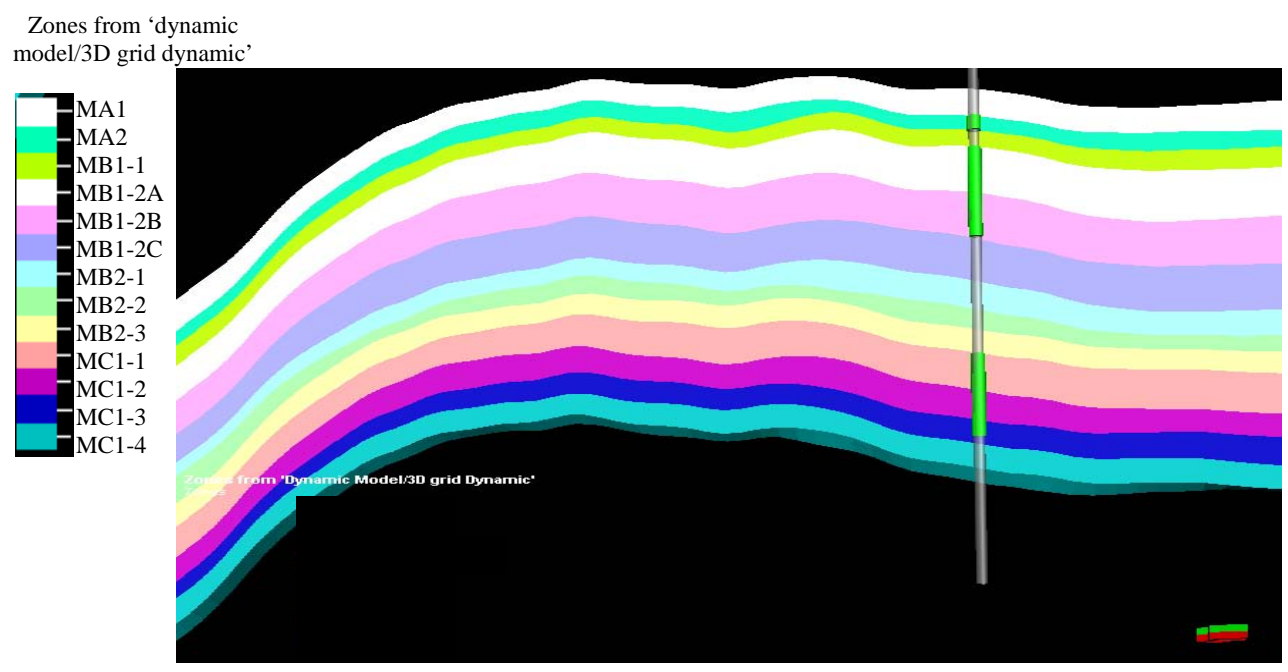

Fig. 7: Target zones for injection in Mishrif crest area

Zones from 'dynamic model/3D grid dynamic'

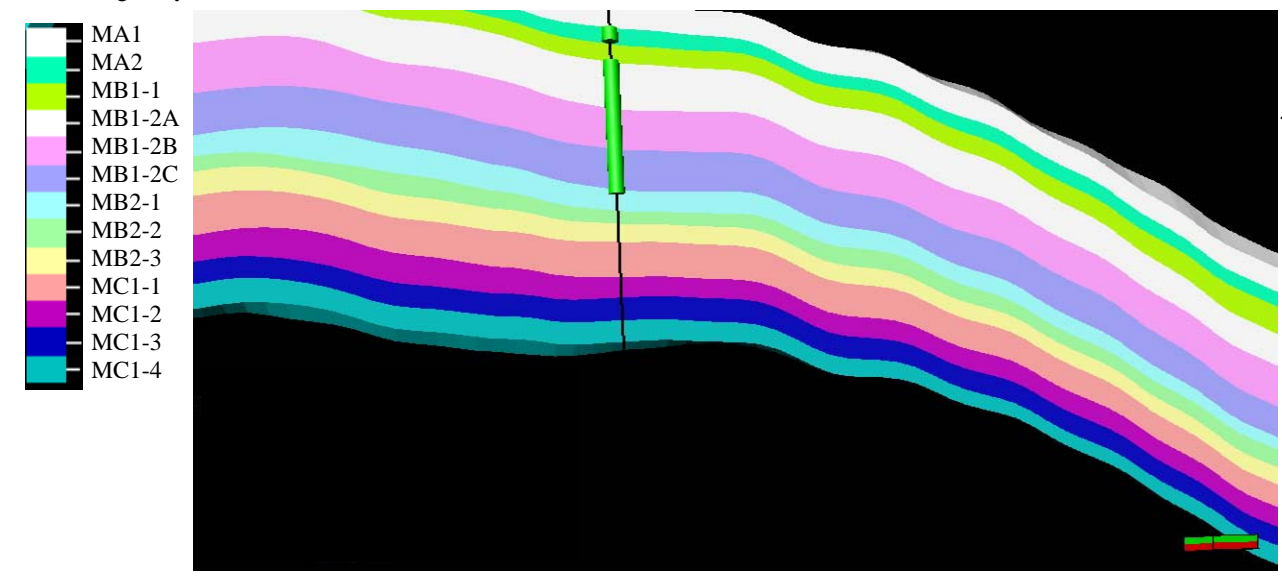

Fig. 8: Target zones for injection in Mishrif flank area

forecasting under waterflooding scheme, the zone-specific injection is found to be the optimal injection mode in the crest area of the reservoir. In this area, the zonal injection is performed by directly injecting water into zones MA2, MB1-2A, MB1-2B, MC1-1, MC1-2 and MC1-3. This mode is executed due to more difficulties to support pressure in the zones with relatively bad properties, especially, through vertical direction (MA2, MB1-2A, MB1-2B) by bottom injection only. In regard other zones (MB1-2C, MB2-1, MB2-2, MB2-3), the injection directly into these zones in the crest area may lead to quick water breakthrough and jeopardize the production of horizontal section. Thus, the pressure of these zones in crest area is supported by bottom water injection into Mishrif MC1 with adequate distance below lateral section in the horizontal producers.
On the other hand, in North West region and near the flank area, most of Mishrif reservoir zones in main units MB2 and MC1 are water bearing zones. Accordingly, commingle injection is the proper mode for purposes of pressure maintenance and oil displacing toward production wells for all production zones in Mishrif excepting main unit MA. This injection mode is carried out by injecting water in zones MB1-2A, MB1-2B, MB1-2C and sometimes MB2-1 to support reservoir pressure by direct injection in the production zones and by bottom injection. Additionally, if waterflooding is needed in the flank and north west region of main unit MA, the commingle injection which mentioned above can be adjusted by adding injection interval in zone MA2 to support reservoir pressure and displace oil in this zone. Figure 7 and 8 display examples of target zones for injection in the crest and flank area of the reservoir, respectively. 


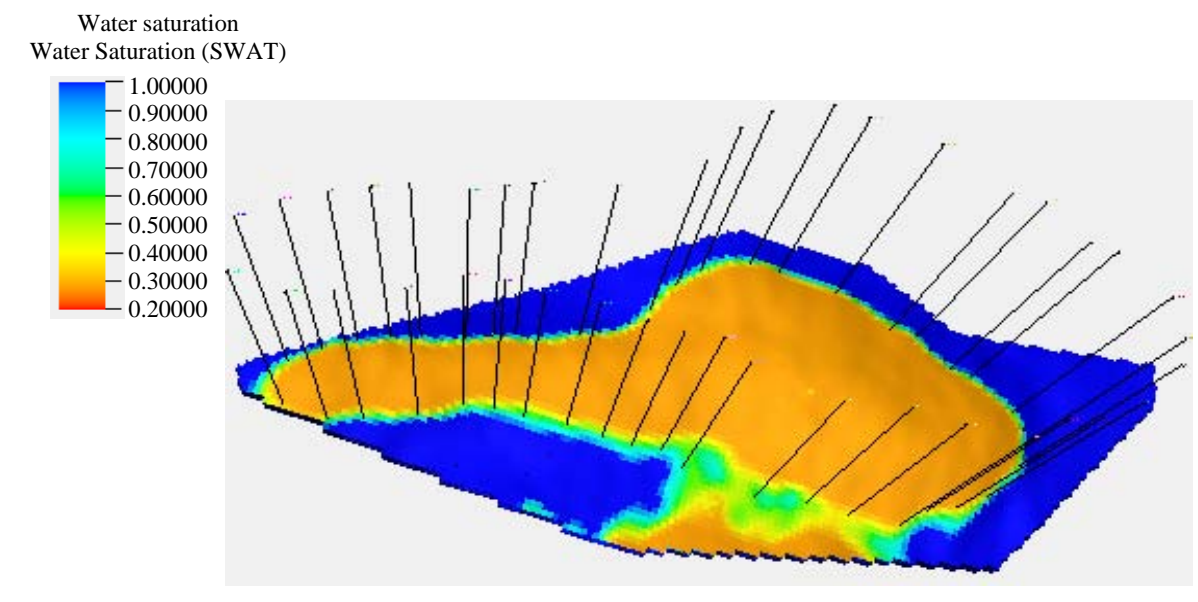

Fig. 9: 3D Distribution of peripheral injectors through zone MB1-2B

Strategy-1; pattern waterflood without peripheral injectors: One of the important steps in designing a waterflooding project is choosing a proper flood pattern. The selection of an appropriate waterflooding pattern for the reservoir partially depends on the location and number of existing production wells. Although, the repeated patterns are commonly used in more fields around the world, irregular patterns and modified patterns are sometimes representing a suitable solution for the reservoir with serious heterogeneity, instability of reservoir distribution as well as various well types penetrate the reservoir such as highly deviated wells, horizontal wells and multilateral wells.

In Mishrif reservoir, up to August, 2017, there are around 100 wells are already drilled in the most important regions of the reservoir with different well configurations. For one injection well pattern, there are various well types including horizontal, multi-lateral, vertical and deviated wells. This high diversity for each well pattern makes the relation between injector and producers is complex and increase the injection uncertainty. Moreover, Mishrif represents a highly heterogeneous and complex carbonate reservoir with poor stability reservoir distribution. Accordingly, repeated patterns can be applied in Mishrif waterflooding model design with big challenges that might resulted by all the concerns mentioned above. However, staggered line drive pattern with some modifications related to row and well spacing can be used to provide a proper pressure support in Mishrif reservoir with valuable recovery design. In this flood pattern, row spacing ranged from 500-750 m (2-3 grid blocks) depending on wells configuration around well pattern, number of new injectors of the proposed strategy and reservoir heterogeneity and discontinuity around the injector. Also, well spacing for vertical well producers ranged from $500-750 \mathrm{~m}$ and for highly deviated and horizontal producers ranged from 1000-500 m.
Additionally, the field water injection rate in this strategy is progressively increased from about 80 MSTBw/D in year 2018 to the maximum value at 755 MSTBw/D in year 2029 and continue to the end of prediction period. To achieve this high production plateau rate and sustain it for reasonable period, the pattern water flood is executed by adding 37 new vertical injection wells and steadily converting of 59 wells from producers to injectors.

Strategy-1P; pattern waterflood plus peripheral injectors: There are big worries regarding of applying a peripheral waterflooding only in Mishrif reservoir that may lead to failure of waterflooding project to provide enough pressure support to producers located in crest area due to existing high pressure sink in this area. The major challenges that can be faced the peripheral waterflooding project in Mishrif reservoir include delay field response to the waterflood; relatively high injection rates needed in low permeability regions, high cost of surface facilities through long distances, difficulty of flood prediction and direction of oil bank and relatively bad reservoir properties in flank area. However, peripheral waterflooding can be proposed to apply simultaneously with pattern flood strategy of strategy-1and evaluate the feasibility of utilizing a peripheral injection wells to more pressure support and improve oil recovery in Mishrif reservoir. Accordingly, in this strategy, 40 vertical injectors will be drilled along reservoir periphery and placed in near the water oil contact to perform a peripheral waterflood process with well spacing ranged from $1500-2000 \mathrm{~m}$ as a supplementary support of the pattern waterflooding in Mishrif reservoir as shown in Fig. 9. All these peripheral injection wells are completed in unit MB1-2C and other upper units to support the pressure around producers near reservoir periphery and displacing oil through these zones toward the interior of the reservoir. 


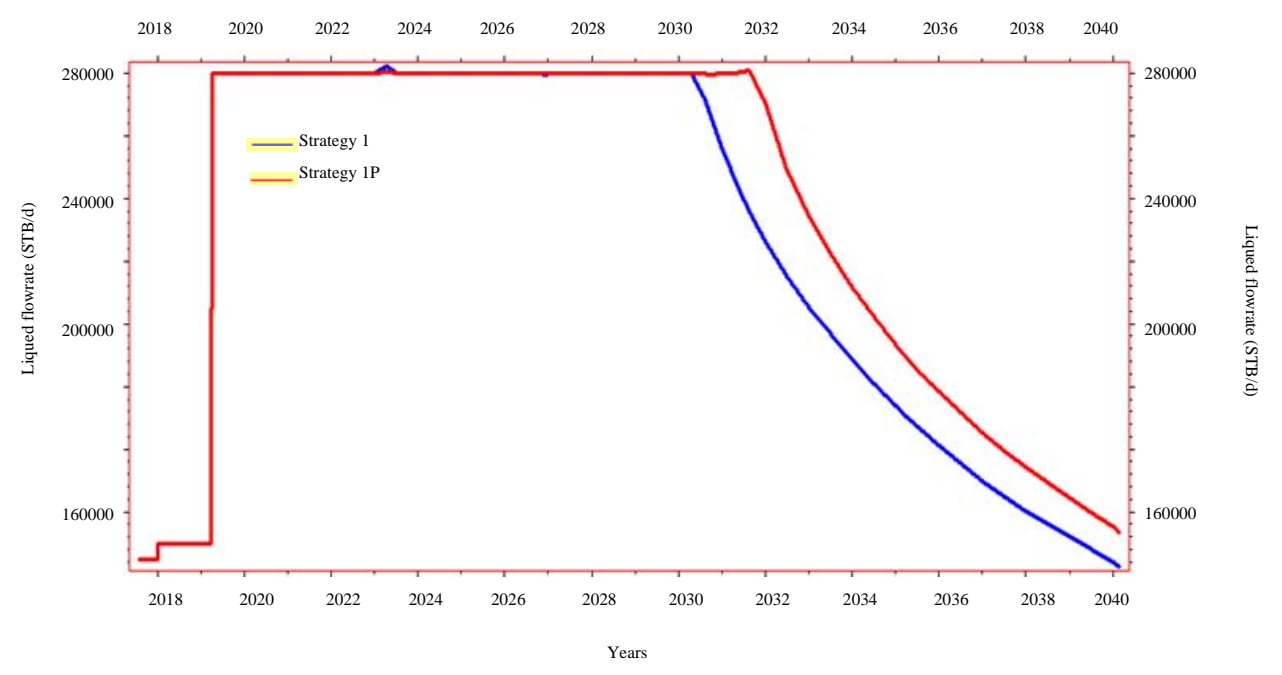

Fig. 10: Field oil production rate for two strategies (1\&1P)

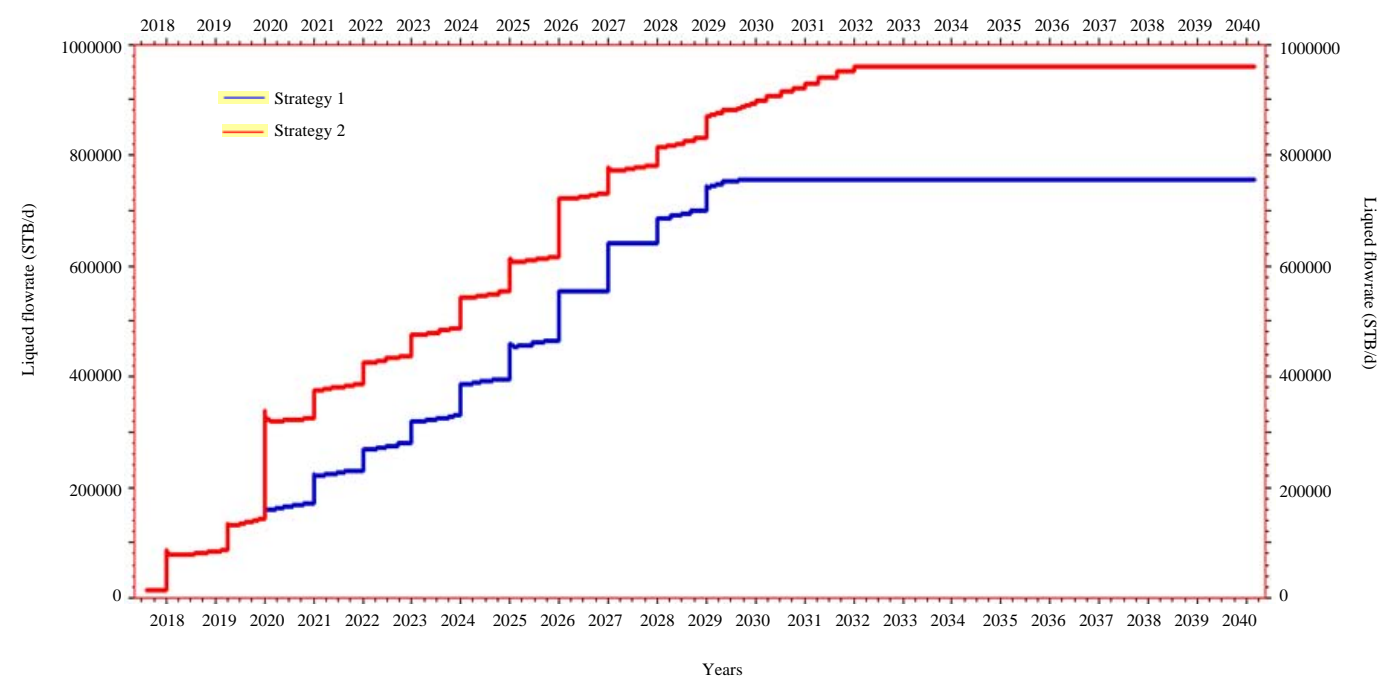

Fig. 11: Field water injection rate for two strategies (1\&1P)

These new peripheral injectors are proposed to drill increasingly from year 2018 to the beginning of 2020 . Consequently, the peripheral waterflooding is starting at early time in January, 2020 and continuing up to the end of prediction period in March, 2040. As a result of adding more peripheral injectors, the maximum field water injection rate for the strategy-1P is $960 \mathrm{MSTB} / \mathrm{D}$ which recorded in year 2032 and stays constant for about 9 years. Also, the maximum well injection rate in this strategy is varied due to upper limit constraint of bottom hole pressure value that setting at 6500 psia for all injectors. Furthermore, other design parameters for the strategy-1P are the same of strategy- 1 , excepting the field water injection rate and total number of injectors Fig. 10 and 11.

\section{RESULTS AND DISCUSSION}

The results of two strategies for applying pattern water flood without and with peripheral waterflooding in Mishrif reservoir are analyzed and in depth studied to assess the feasibility of using an additional sustenance to pattern water flood for pressure maintenance and improve oil recovery. Hence, the results of strategy- 1 are compared with results of strategy- $1 \mathrm{P}$ which includes the new peripheral injection wells. This comparison is carried out through plotting oil production rate, total water injection rate, cumulative oil production, cumulative water injected, cumulative water production, reservoir pressure and field water cut with time, Fig. 12-16. 


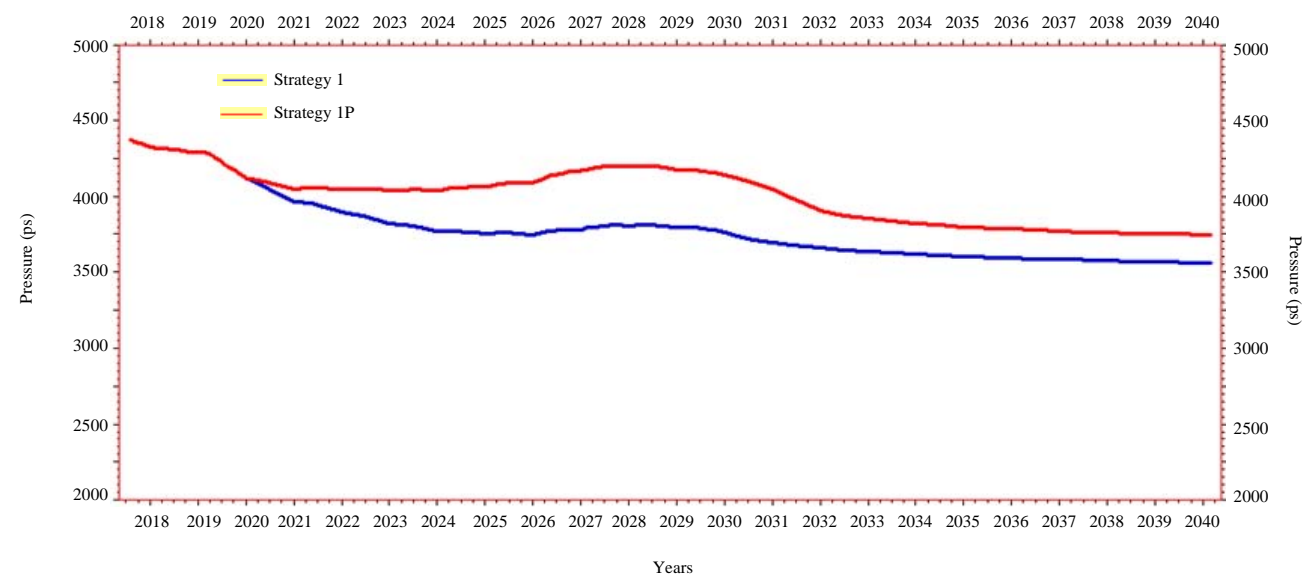

Fig. 12: Field pressure for two strategies (1\&1P)

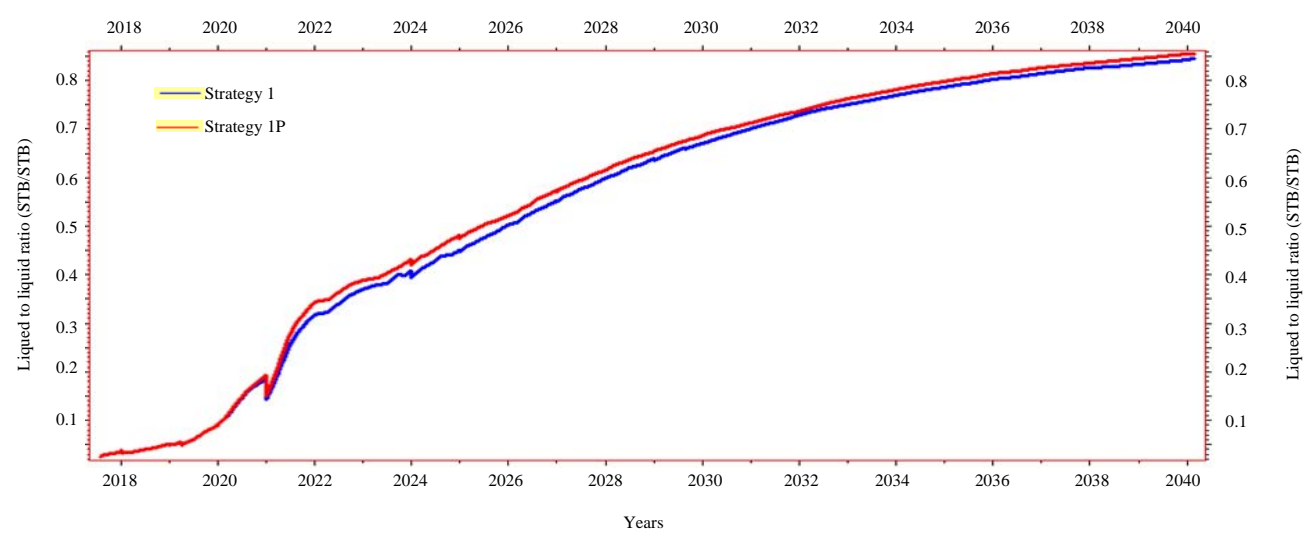

Fig. 13: Field water cut for two strategies (1\&1P)

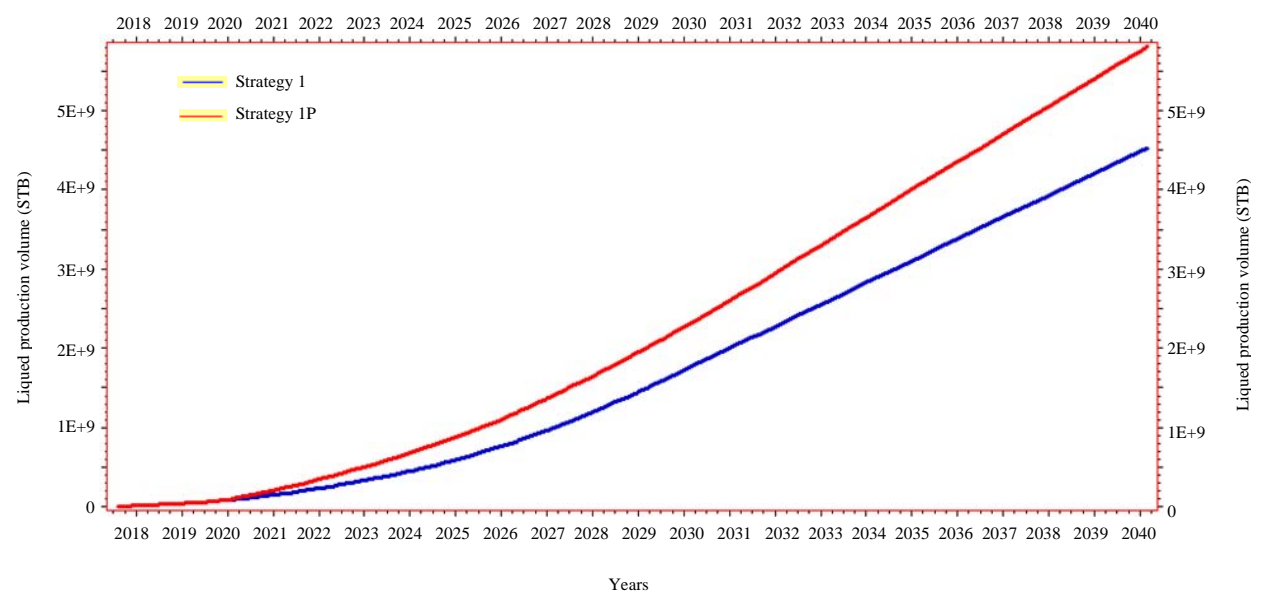

Fig. 14: Field cumulative water injected for two strategies(1\&1P)

Table 1 presents the total number of injectors in each proposed strategy and a length of production plateau period as well as the Field Oil Production Rate (FOPR), Cumulative Water Injected
(CWI), Field Pressure (FPR), Field Water Cut (FWCT) and Field Recovery Factor (FRF) at the end of prediction period for both two strategies $1 \& 1 \mathrm{P}$ and their differences Table 1. 
Table 1: Results of peripheral waterflooding feasibility in strategy-1

\begin{tabular}{llll}
\hline Items & Srtategy-1 & Srtategy-1P & Difference \\
\hline Total No. of injectors & 96 & 136 & +40 \\
Plateau length (years) & 11 & 12.4 & +1.4 \\
FOPR (MSTB/D) & 142.7 & 153.6 & +10.9 \\
CWI (MMSTBw) & 4523.59 & 5808.34 & +1284.75 \\
FPR (Psia) & 3559.2 & 3748.6 & +189.4 \\
FWCT (\%) & 84.44 & 85.51 & +1.06 \\
FRF (\%) & 22.82 & 23.59 & +0.77 \\
\hline
\end{tabular}

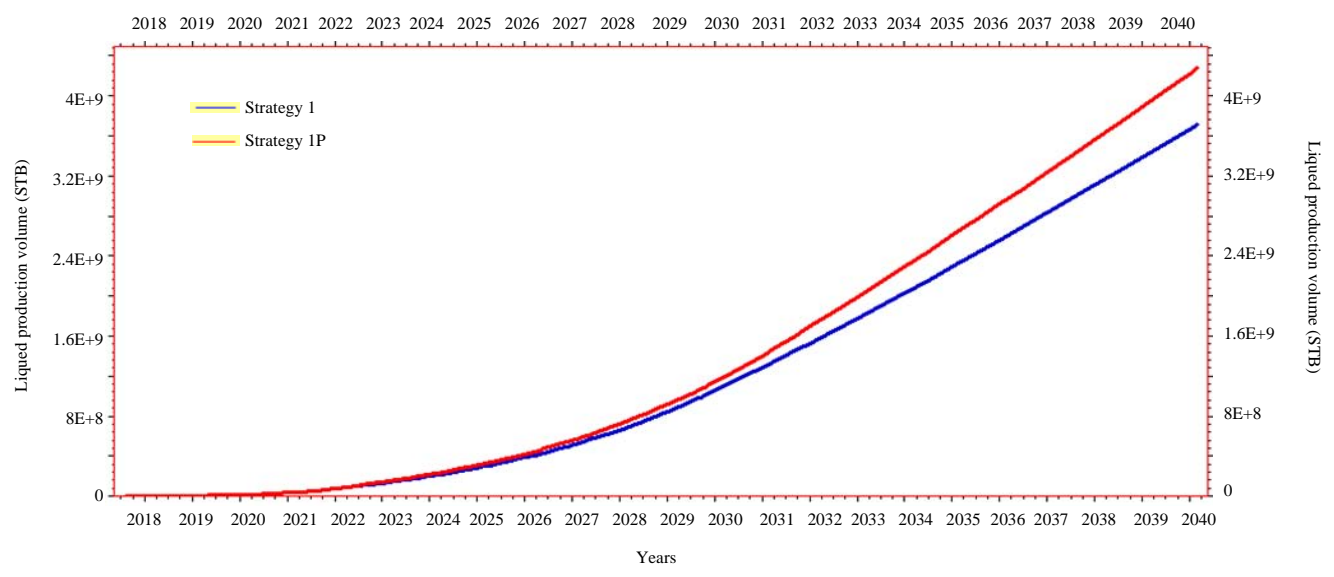

Fig. 15: Field cumulative water production for two strategies(1\&1P)

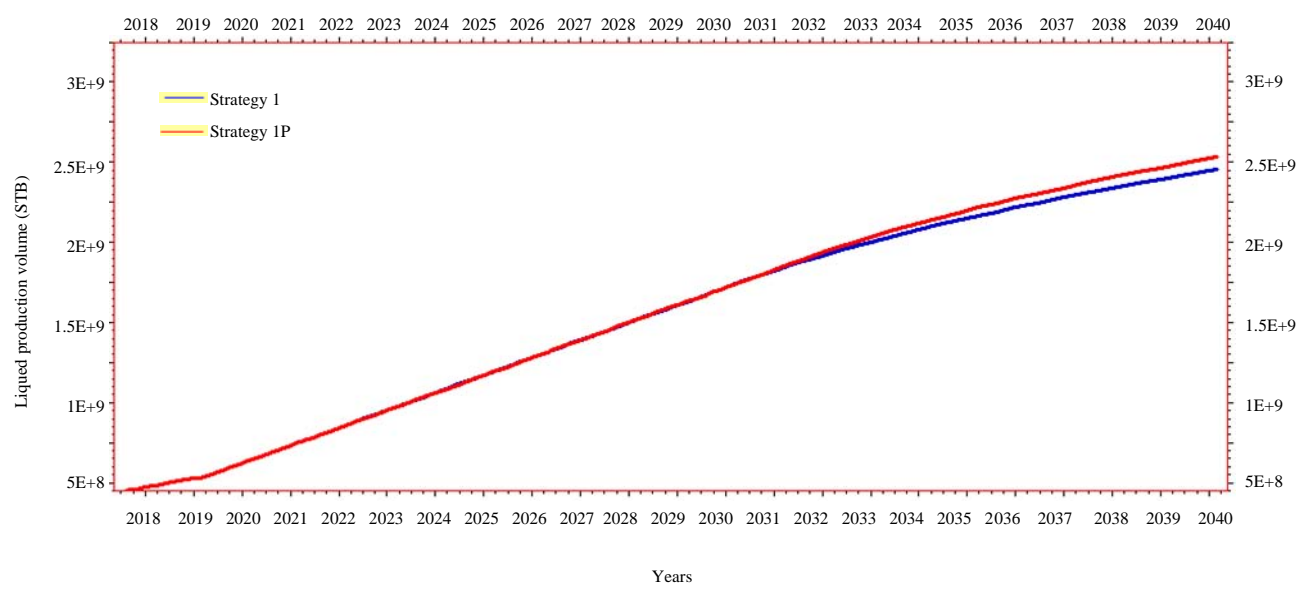

Fig. 16: Field cumulative oil production for two strategies (1\&1P)

From the Fig. 16 and table above, there are many results and observations that can be presented. Regarding of production plateau period, the strategy of pattern water flood with peripheral injectors is slightly better than this strategy without peripheral wells. Adding peripheral injection wells expands the production plateau period for strategy- 1 by around 1.4 years only.

The field pressure is maintained above saturation pressure of Mishrif reservoir for both strategies-1\& 1P. However, there are a moderate increase in whole reservoir pressure along prediction period through strategy-1P in comparison of strategy-1. For instance, the field pressure value difference between two strategies at the end of prediction period is around 190 psia.

Along prediction period, the field water cut in strategy-1P is slightly more than that in strategy- 1 . At the end of prediction period, the field water cut of strategy-1P is more than that of strategy- 1 with $1.06 \%$. In general, the field water cut in both strategies-1\&1P is less than economic upper limit at $90 \%$. 


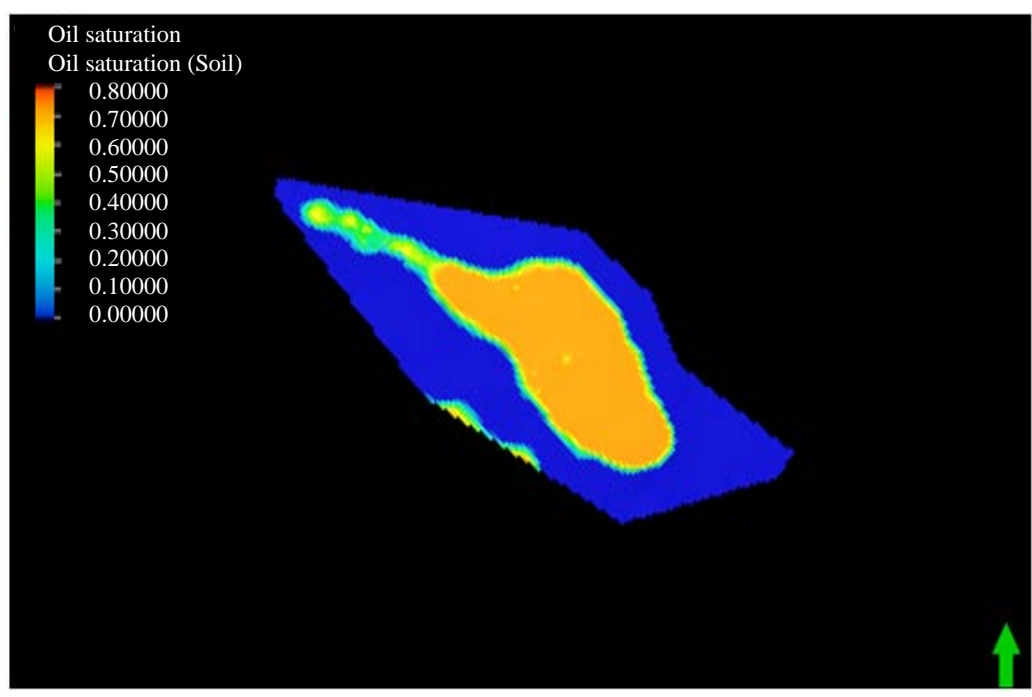

Fig. 17: Distribution of remaining oil saturation in unit MB1-2C before waterflooding

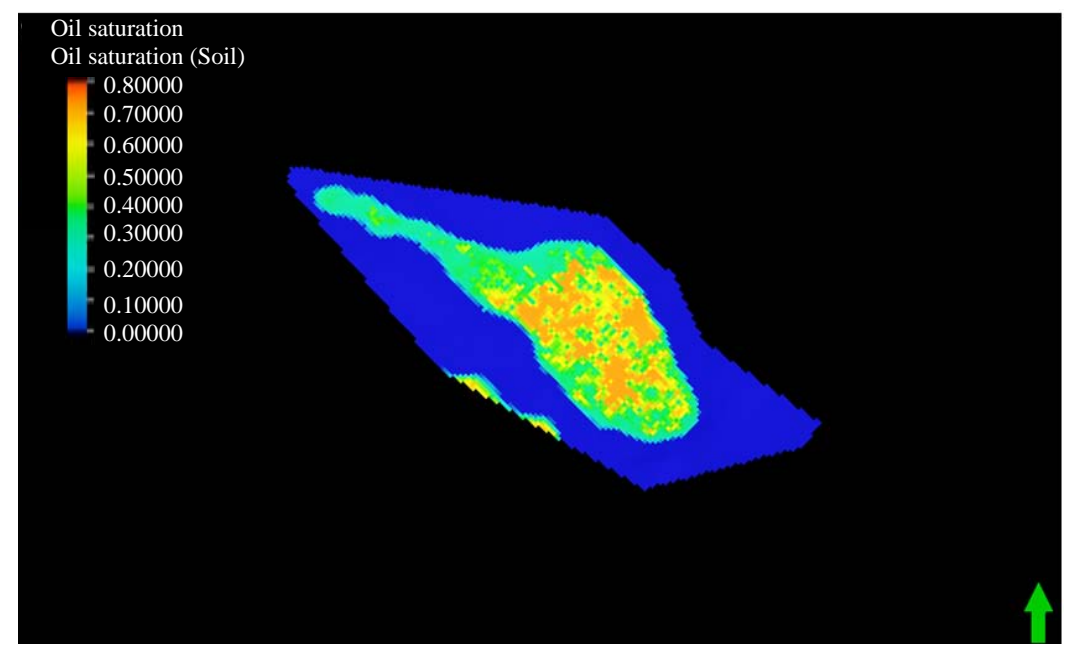

Fig. 18: Distribution of remaining oil saturation in unit MB1-2C after waterflooding in strategy-1

Regarding of total water injected volume, the pattern water flood strategy with peripheral injectors is required much water than that of this strategy without peripheral wells. Up to end of prediction period, only peripheral wells need around 1.285 MMMSTBw of water to suport pattern water flood in strategy-1P.

In term of field cumulative oil productionand final oil recovery, only the peripheral water flood added about 76 MMSTB. Thus, the final oil recovery factor of strategy-1P is slightly more than that in strategy 1 where the difference between them is around $0.77 \%$ only.

As a discussion of all these results above, the increasing of cumulative water injected volume in
strategy-1P is considerably high and required further water sources and additional costs for many peripheral water injection operations. However, the profit of adding peripheral wells to pattern water flood is comparatively slight through increasing the final oil recovery and production plateau period as well as moderately support of average reservoir pressure. Furthermore, there is no observable difference in the remaining oil saturation after waterflooding for both two strategies in most of reservoir zones. For example, Fig. 17-19 display the distribution of remaining oil saturation in unit MB12C before and after waterflooding for both two strategies. 


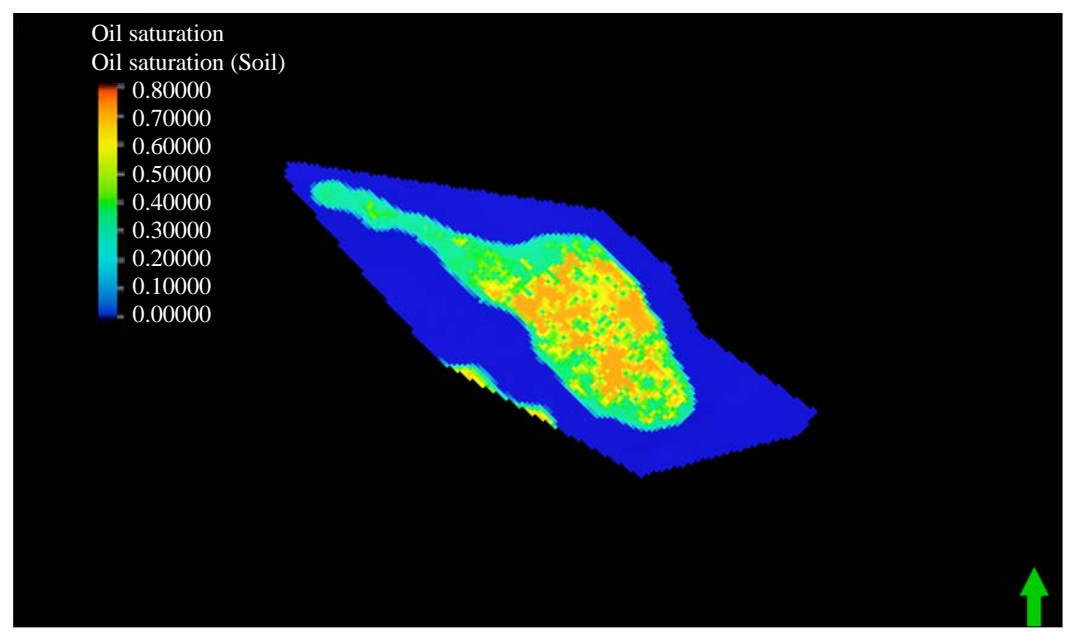

Fig. 19: Distribution of remaining oil saturation in unit MB1-2C after waterflooding in strategy-1P

For coarsely estimations, each one STB of oil produced by adding peripheral injection wells to pattern water flood needs about 17 STBw of water injected if assuming all other parameters and conditions have a marginal influence on these calculations.

\section{CONCLUSION}

Pattern waterflooding with production plateau rate of $300 \mathrm{MSTB} / \mathrm{D}$ and final recovery of $22.82 \%$ is the optimal strategy for Mishrif development under waterflooding with restricted water sources situation. In regarding of of adding peripheral Injectors to pattern waterflood, a peripheral waterflooding is unfeasible strategy as supplementary support to pattern water flood for pressure maintenance and improving oil recovery. This strategy requires a great amount of water injected with a small profit in increasing final oil recovery, lengthening production plateau duration, and increasing reservoir pressure support as a result of high heterogeneity and relatively low permeability in flank area of Mishrif reservoir.

\section{REFERENCES}

Ahmed, T., 2010. Reservoir Engineering Handbook. 4th Edn., Gulf Professional Publishing, Texas, USA., ISBN:978-1-85617-803-7, Pages: 1472.

Akbar, M., B. Vissapragada, A.H. Alghamdi, D. Allen and M. Herron et al., 2000. A snapshot of carbonate reservoir evaluation. Oilfield Rev., 12: 20-41.

Liu, D. and J. Sun, 2017. The Control Theory and Application for Well Pattern Optimization of Heterogeneous Sandstone Reservoirs. Springer, Berlin, Heidelberg, Germany, ISBN:978-3-66253285-0, Pages: 383.

Singh, S.P. and O.G. Kiel, 1982. Waterflood design (pattern, rate and timing). Proceedings of the International Symposium on Petroleum Exhibition and Technical, March 17-24, 1982, Society of Petroleum Engineers, Beijing, China, pp: $1-17$.

Smith, J.T. and W.M. Cobb, 1997. Waterflooding. Petroleum Technology Transfer Council, Houston, Texas, USA., Pages: 584. 